\title{
INCREASING THE EFFICIENCY OF MARINE ENERGY CONVERSION
}

\author{
Violeta-Vali CIUCUR, \\ ${ }^{1}$ Constanta Maritime University, Faculty of Naval Electro-Mechanics, 104 Mircea cel Batran Street, 900663, Constanta, \\ Romania, e-mail violeta.ciucur@cmu-edu.eu
}

\begin{abstract}
New approaches need to be taken into account in adopting the configuration of residual heat recovery systems, design, operation and control and to consider equipment and the energy conversion process in the perspective of integrated systems in order to increase measurable energy efficiency in existing marine energy systems as well as other new systems.

The way of improving energy efficiency is strongly promoted by the largest companies, which produce marine equipment and main engines for ships.

Residual heat recovery systems are promising solutions for efficient, cost-effective, ecological power and propulsion onboard ocean ships.
\end{abstract}

Key words: energy efficiency, main engines, ships.

\section{INTRODUCTION}

To cover the needs of the propulsion, loadingunloading manoeuvres, freshwater production, space heating, cooling, passenger comforts are needed on board many forms of energy.

\section{FORMS OF ENERGY COMING ON BOARD SHIPS}

The greatest interest in reducing emissions and reducing ship operating costs are shipping companies.

This requires taking measures to ensure the optimal use of the fuel used for the main ship engines on the ships.

Usually, energy systems on the ship transforms chemical fuel energy - primary energy source - in those forms that are needed on board ships.

The ships are autonomous resource factories that sail at sea and incorporate a plurality of components and systems.

The energy autonomy of the ship is a reality because all resources, including different forms of energy, required during a voyage, must be stored or produced aboard the ship.

In general, there are a number of energy conversion processes based on the transformation of a primary energy source (today fuel, in the past wind, renewable sources in the future) in heat, in kinetic energy, electricity and ultimately to the required propulsion force.

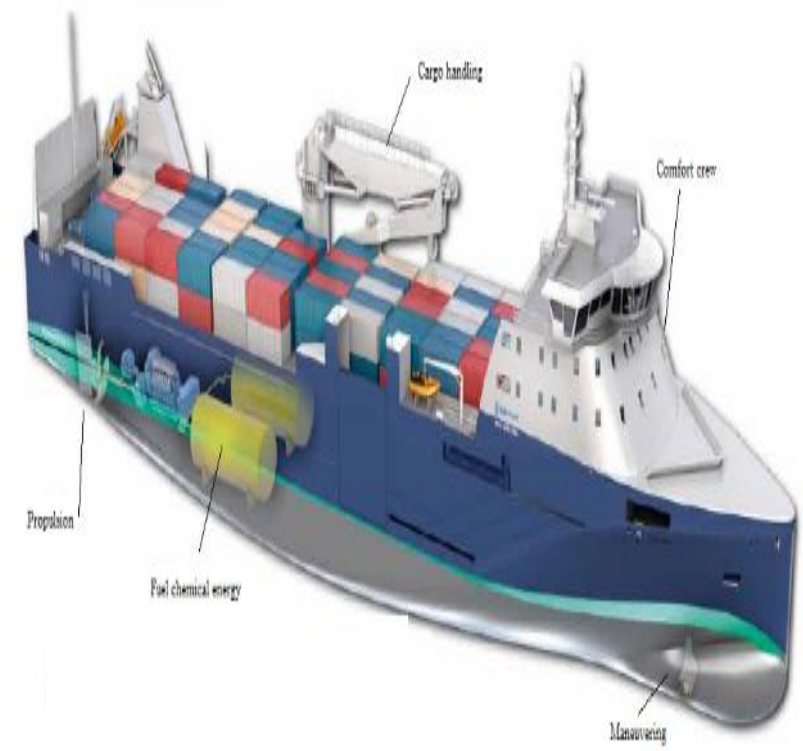

Figure 1 Energy forms found on board ships 
A multitude of other energy conversion processes is carried out to cover the needs of the ship for electricity, heat and all other forms of energy.

All these types of energies are the energy conversion system on the ship.

Steam boilers or gas turbines convert fuel energy, auxiliary machines, internal combustion engines turn fuel or steam energy into mechanical energy.

Propulsion facilities take over energy and convert in energy to overcome ship resistance and ship movement on the desired route at a desired speed.

There are also energy distribution systems for consumers on board the ship.

In other news, the efficiency of the main engines has increased and the energy efficiency of fuel is about $50 \%$, which has led to a lower temperature corresponding to the exhaust gas after turbochargers.

The main objective for the ship owner is to reduce the operational costs of the ship and to a further reduction in $\mathrm{CO}_{2}$ emissions.[6]

\section{RESIDUAL HEAT RECOVERY SYSTEMS (WHRS)}

Residual Heat Recovery Systems (WHRS) are a revolutionary energy saving system that recovers and reuses the energy of the main engine exhaust gases.

WHRS optimizes thermal efficiency by automatically adjusting power depending on on-board electricity demand.

The residual heat recovery system increases the possibilities for producing electricity from exhaust gases and an improvement in total efficiency, as well as a slight reduction in main engine efficiency.

At a speed engine, the low speed of the exhaust gas flows through the main turbocharger of the engine through an exhaust gas bypass.

The main engine exhaust gas is one of the most important of the heat sources, the waste of a ship due to heat and temperature flow.

The main source of the residual heat of a main engine is the dissipation of the heat of exhaust gas, which represents about half of the total residual heat, or about $25 \%$ of the total fuel energy.[4]

The waste heat recovery system (WHRS) on a main engine ship is similar for buildings that use cogeneration units.

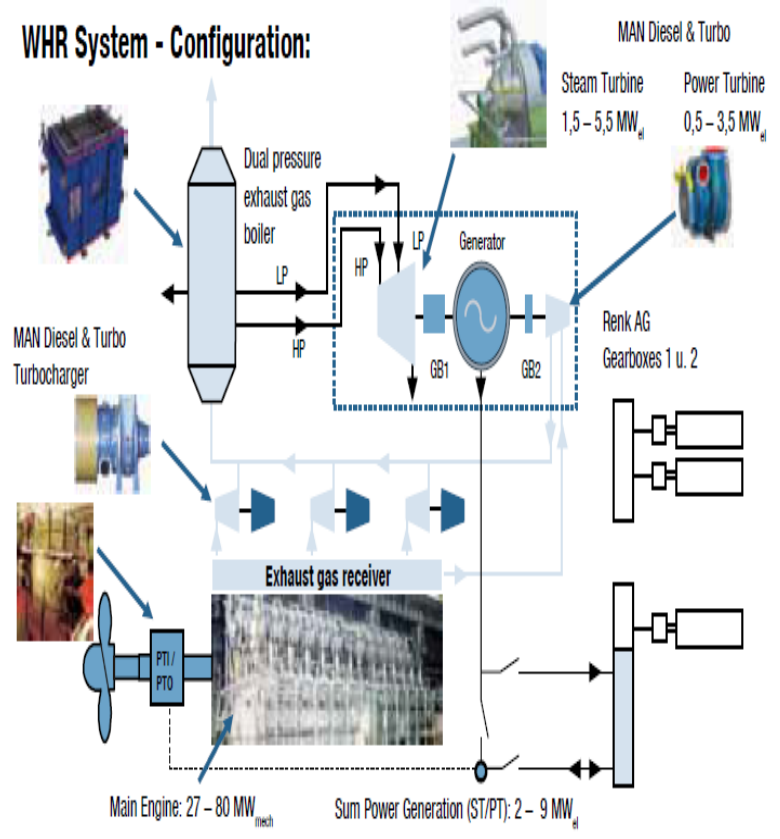

Figure 2 Waste heat recovery systems

The Energy Efficiency Design Index aims to promote much more efficient use of energy [5]:

$$
E E D_{\text {atinsI }}=\frac{\mathrm{CO}_{2 \mathrm{emisii}}}{\text { work }}=\frac{P \cdot S F C \cdot C_{F}}{f_{i} \cdot \operatorname{Capacity} \cdot V_{\text {ref }} f_{w}}
$$

where:

$\mathrm{C}_{\mathrm{F}^{-}}$conversion between fuel and $\mathrm{CO}_{2}$;

SFC-Specific fuel consumption;

$\mathrm{f}_{\mathrm{i}}$-the capacity factor;

$\mathrm{f}_{\mathrm{w}}-\mathrm{a}$ non-dimensional coefficient that indicates the decrease in speed in high conditions represented by wave height, the frequency and speed of the wind;

$\mathrm{P}, V_{\text {ref }}$ and capacity -a consistent set of $75 \%$ of the main engine power and the corresponding speed, when the ship carry to its full capacity in calm weather;

The numerator of this function includes the sum of the main engine emissions, auxiliary motor and the motor axle generator, minus emission reductions in efficient technologies;

$$
\begin{aligned}
& \quad \text { DI atins } \leq \quad \text { DIrequisit }=(1-X / 100)= \\
& x \text { Reference Line Value. }
\end{aligned}
$$

$\mathrm{X}$ - EEDI requested reduction factor, compared to EEDI 's reference line.

Reference line values are calculated as follows: 
where:

$$
D I=a * b^{-C} .
$$

a, b and c - parameters that appear for different types of ships.

The EEDI formula consists of four terms that address different ship design criteria.

Emissions $\mathrm{CO}_{2}$, Main Engine:

$$
\left(\prod_{j=1}^{n} f_{j}\right)\left(\sum_{i=1}^{n_{M E}} P_{M E(i)} * C_{F M E(i)} * S F C_{M E(i)}\right)
$$

Emission reduction $\mathrm{CO}_{2}$, thanks to innovative technology:

$$
\left(\sum_{i=1}^{n_{e f f}} f_{e f f(i)} * P_{e f f(i)} * C_{F M E} * S F C_{M E}\right)
$$

Electricity efficiency:

$$
\left({ }_{i=1}^{M} f_{j} \sum_{i=1}^{n^{P T I}} P_{P T I_{(i)}}-\sum_{f_{o f f(i)}} P_{A E_{o f f(i)}}\right) C_{F A E} * S F C_{A E},(6)
$$

where:

$\mathrm{f}_{\mathrm{j}}$ - correction factor to account for ship-specific design elements, if design elements are not installed, the factor is set to 1 .

\section{CONCLUSIONS}

Currently, indincessing energy efficiency of the ship only provides information on emissions of $\mathrm{CO}_{2}$ emissions in fuel consumption, then resulting in energy but not how much energy is used. [1]

This situation of EEDI is similar to EPC energy performance certificates of buildings

A strategy for Naval Energy Efficiency is welcome but regulation only monitors fuel consumption instead of this direct reduction, and covers $\mathrm{CO}_{2}$ and not atmospheric pollutants such as $\mathrm{SO}_{2}$, or $\mathrm{NO}_{x}$. [2]

A simple analogy with the European Ecological Design or Energy Performance of Buildings indicates the lack of ecological labels of ships.

All types of ships can use clean fuel (gas or hydrogen) in the future and is expected to obtain the green ship by using the efficient use of renewable technologies.

The use of renewable energy technologies is not a common practice.[7]

Even if the market can provide adequate technologies nor the obligation is unsuccessful, neither the operations of simulating the growth and use of renewable energy fails in particular hydrogen technology for new ships.

In the future of shipping considered to be green, the widespread use of wind, solar and electrical energy will be encountered to help propel ships and power vessels of all sizes.

Eventually, EEDI is a non-prescriptive, performance-based mechanism that allows the choice of technologies to be used on a ship to be the specific industry responsibility.

As long as the level required by energy efficiency is achieved, ship designers and shipbuilders are free to use the most cost-effective solutions for ships and comply with the rules.

\section{REFERENCES}

[1] Buhaug, Corbett, J.J.-Second IMO GHG study 2009International Maritime Organization, London, 2009.

[2] Directive 2012/27/EU of the European Parliament and of the Council of 25 October 2012 on energy efficiency, amending Directives 2009/125/EC and 2010/30/EU and repealing Directives 2004/8/EC and 2006/32/EC (2012) OJ L315, pp. 1-56.

[3] Directive 2010/31/EU of the European Parliament and of the Council of 19 May 2010 on the energy performance of buildings (2010), OJ L 153, pp. 1335 .

[4] http://www.wartsila.com/en/engines/low-speedengines/rt-flex96c

[5] Zabi Bazari, Lloyd's Register, London, UK and Tore Longva, DNV, Oslo, Norway -Assessment of IMO mandated energy efficiency measures for international shipping, -31 October 2011

[6] TCS-PTG Savings with Extra Power, MAN Diesel \& Turbo SE, Augsburg, December 2011 Copyright (C) MAN Diesel \& Turbo.

[7] G. G. Dimopoulos, C. A. Georgopoulou and N. M. P. Kakalis, 2011, Modelling and optimisation of an integrated marine combined cycle system, Proceedings of 24th International Conference on Energy, Cost, Optimization, Simulation and 
Environmental Impact of Energy Systems (ECOS), 2-5 July, Novi-Sad, Serbia.

[8]http://www.imo.org/OurWork/Environment/Pollution Prevention/AirPollution/Pages/Technical-and-

Operational-Measures.aspx

[9] Amendments to MARPOL ANNEX VI on regulations for the prevention of air pollution from ships by inclusion of new regulations on energy efficiency for shipsresolution MEPC.203(62) Adopted on 15 July 2011.

[10] http://www.epa.gov/cleanenergy/energyresources/calculator.html\#results

[11]

https://www.google.ro/\#q=energy+efficciency+desi gn+index 